\title{
Effect of parenteral administration of oestrogen and progesterone on the glycogen metabolism of mouse morulae-early blastocysts in vivo*
}

\author{
W. R. Edirisinghe† and R. G. Wales \\ School of Veterinary Studies, Murdoch University, Murdoch, Western Australia 6150, Australia
}

\begin{abstract}
Summary. Morulae-early blastocysts were pulse-labelled with radioactive glucose and subsequently transferred for $24 \mathrm{~h}$ to ovariectomized recipients maintained on different hormone regimens. Embryos transferred to recipients treated with progesterone utilized more glycogen than did those incubated in untreated controls. Treatment with oestrogen alone had no significant effect on glycogen turnover of transferred embryos and, when given in combination with progesterone, antagonized the effect of progesterone. Priming doses of oestrogen given $>4$ days before progesterone had no significant effect on the response to progesterone.

The results indicate that the high levels of progesterone circulating in the mother before implantation cause glycogen degradation in the embryo and account for the low glycogen content of uterine embryos compared to those cultured in vitro in the presence of glucose.
\end{abstract}

\section{Introduction}

Late preimplantation mouse embryos utilize the majority of preformed glycogen when transferred to the reproductive tract of synchronized pseudopregnant recipients whereas those cultured in vitro conserve most of their intracellular glycogen stores (Edirisinghe, Wales \& Pike, 1984a). It would therefore appear that the uterine environment can exert an influence upon the metabolic pathways operative in the embryo at this time.

Ovarian steroids may be involved in this effect of the uterus on the embryo because they are of primary importance in bringing about the synchronization of growth and development of the reproductive tract with that of the early, free-living embryo. Progesterone dominates during most of the preimplantation period but in murids a peak of oestrogen occurs at Day 4 of pregnancy and is required for the initiation of implantation (Shaikh, 1971; McCormack \& Greenwald, 1974). Investigations using exogenous steroids in ovariectomized mice have indicated that an initial peak of oestrogen (priming oestrogen) is important in sensitizing the endometrium for the subsequent action of progesterone and oestrogen (nidatory hormones) to give maximum deciduoma formation (Finn \& Martin, 1970).

The endometrium shows structural (Finn, 1977) and biochemical (Yochim, 1975) changes in response to the changing patterns of steroid secretion and there are changes in the volume and composition of luminal fluids as a result of the hormonal environment (Restall, 1966; Restall \& Wales, 1966, 1968; Iritani, Gomes \& VanDemark, 1969; Iritani, Nishikawa, Gomes \& Van Demark, 1971; Wales \& Restall, 1971; Tantayaporn, Mallikarjuneswara, de Carlo \& Clemetson, 1974 ; Beier, 1974; Surani, 1975; Fishel, 1979). Control of the metabolism of the embryo by ovarian

* Reprint requests to Professor R. G. Wales.

+ Present address: Department of Obstetrics \& Gynaecology, National University of Singapore, Kandang Kerbau Hospital, Hampshire Road, Singapore 0821, Malaysia. 
hormones has also been demonstrated. For example, diapausing mouse embryos show a low rate of incorporation of $\left[{ }^{35} \mathrm{~S}\right]$ methionine (Weitlauf \& Greenwald, 1968) and a low rate of production of $\mathrm{CO}_{2}$ (Menke \& McLaren, 1970). Both of these metabolic processes increase after administration of oestrogen and progesterone (Weitlauf, 1974). Ozias \& Weitlauf (1971) have studied the effect of ovarian hormones on the total glycogen content of blastocysts collected from ovariectomized pregnant mice treated with oestrogen and progesterone:oestrogen increased and progesterone decreased the amount of glycogen in the embryos.

In the present experiments, the control of the metabolism of embryonic glycogen by ovarian hormones at the late stages of preimplantation development has been investigated.

\section{Materials and Methods}

General. Female mice were induced to superovulate and morula-early blastocyst-stage embryos were collected $96 \mathrm{~h}$ after the hCG injection, as described previously (Pike \& Wales, 1982). For collection, washing and culture of embryos the basic culture medium used was a modified Krebs'Ringer bicarbonate solution supplemented with $25 \mathrm{~mm}$-lactate and $0.25 \mathrm{~mm}$-pyruvate, as used in previous studies (Pike \& Wales, 1982). All in-vitro incubations were carried out in droplets of medium under paraffin oil at $37^{\circ} \mathrm{C}$ in a humidified atmosphere of $5 \% \mathrm{CO}_{2}: 95 \%$ air.

Pulse labelling of embryos. The morula-early blastocyst embryos were pulse labelled by culturing for $2 \mathrm{~h}$ in a medium containing $0.28 \mathrm{~mm}-\left[\mathrm{U}-{ }^{14} \mathrm{C}\right]$ glucose with a specific activity of $1.11 \mathrm{MBq} / \mu \mathrm{mol}$. After labelling, the embryos were recovered and washed through two changes $(2 \mathrm{ml} /$ wash $)$ of medium identical to that used in culture but containing non-radioactive glucose. Some of the pulselabelled embryos were collected and stored at $-70^{\circ} \mathrm{C}$ for fractionation to study the incorporation of label during the $2-\mathrm{h}$ pulse period.

Chase in vitro. Approximately $30-40$ of the pulse-labelled embryos were placed in droplets of medium containing $0.28 \mathrm{~mm}$-non-radioactive glucose and chase-cultured for $24 \mathrm{~h}$ under standard culture conditions. After culture the embryos were washed through two changes $(2 \mathrm{ml} /$ wash $)$ of medium identical to that used during chase and stored for fractionation.

Chase in vivo. In Exp. 1 pulse-labelled embryos were transferred into the uteri of ovariectomized mice that had been treated with ovarian hormones. Hormone treatments of the ovariectomized animals began 10 days after surgery. The ovariectomized mice (3-4 in each group) received the following hormonal treatments by s.c. injections in $0 \cdot 1 \mathrm{ml}$ arachis oil every $24 \mathrm{~h}$ for 3 days: Group 1, arachis oil only (control); Group 2, $25 \mathrm{ng}$ oestradiol benzoate; Group 3, $2.0 \mathrm{mg}$ progesterone; and Group 4, $25 \mathrm{ng}$ oestradiol benzoate $+2.0 \mathrm{mg}$ progesterone.

Transfer of embryos to the uteri of treated animals was carried out on the 3 rd day of hormone treatment. Approximately 20 morulae-early blastocysts, pulse-labelled in vitro for $2 \mathrm{~h}$, were transferred into each uterine horn of mice in each treatment group. The embryos were recovered $24 \mathrm{~h}$ after transfer by flushing the uteri with culture medium. The percentage recovery of embryos from each treatment group was 16,9,14 and 7 from Groups 1 to 4 respectively. The embryos were washed twice ( $2 \mathrm{ml} /$ wash) through medium containing $0.28 \mathrm{~mm}$-non-radioactive glucose and stored at $-70^{\circ} \mathrm{C}$ before fractionation.

In Exp. 2 the effect of oestrogen priming on the utilization of glycogen by transferred embryos was studied. Embryos were transferred to ovariectomized mice that had been given a priming dose of oestrogen before the nidatory hormone and the results were compared with those after transfer to unprimed recipients. The time interval and the doses of oestrogen used for priming in this experiment have been shown to cause maximal responsiveness of the uterus to subsequent treatment with nidatory hormones (Finn \& Martin, 1972). The ovariectomized mice were allotted to two groups. 
Group A mice were treated daily with arachis oil only $(0.1 \mathrm{ml})$ for 3 days. Group B mice were given priming injections of $100 \mathrm{ng}$ oestradiol benzoate in $0.1 \mathrm{ml}$ arachis oil daily for these 3 days. Four days after the last priming injection, the mice given arachis oil only were further divided into two sub-groups making a total of 3 groups ( 2 unprimed, 1 primed, with 3-4 mice in each group) and the following hormone regimens were administered daily for 3 days: Group Al, unprimed + arachis oil (control); Group A2, unprimed $+2.0 \mathrm{mg}$ progesterone; and Group B, primed $+2.0 \mathrm{mg}$ progesterone. Embryos previously pulse-labelled in vitro for $2 \mathrm{~h}$ were transferred $(\sim 10$ embryos/uterine horn) on the $3 \mathrm{rd}$ day of the nidatory hormone treatment. The embryos were recovered $24 \mathrm{~h}$ after transfer, washed and stored for fractionation. The percentage recovery of embryos from Groups A1, A2 and B was 30, 29 and 22 respectively.

Fractionation of embryos. Embryos obtained from different treatment groups were fractionated into major biochemical fractions using the extraction procedure described previously (Edirisinghe et al., 1984b). The radioactivity in these fractions was then determined using scintillation spectrometry and the glucose carbon incorporated (in pg atoms/embryo) was calculated.

\section{Results}

\section{Experiment 1}

As shown in Table 1 embryos transferred to ovariectomized mice treated with progesterone had a much lower accumulation of glucose carbon in the acid-soluble glycogen fraction than did those

Table 1. Glucose carbon accumulated in various biochemical fractions of morulae-early blastocysts cultured for $2 \mathrm{~h}$ in a medium containing $0 \cdot 28 \mathrm{mM}-\left[\mathrm{U}-{ }^{14} \mathrm{C}\right] \mathrm{glucose}$ followed by 24-h chase in ovariectomized recipients

\begin{tabular}{|c|c|c|c|c|c|}
\hline \multirow[b]{3}{*}{ Group } & \multirow{3}{*}{$\begin{array}{c}\text { Treatment of } \\
\text { Recipient }\end{array}$} & \multicolumn{4}{|c|}{ Accumulation of glucose carbon (pg atoms/embryo) in : } \\
\hline & & \multirow[b]{2}{*}{$\mathbf{N}+$} & \multicolumn{2}{|c|}{ Acid-soluble fraction } & \multirow{2}{*}{$\begin{array}{l}\text { Acid-insoluble } \\
\text { fraction }\end{array}$} \\
\hline & & & Glycogen & Non-glycogen & \\
\hline 1 & No hormone & 14 & $6.54 \pm 0.82$ & $1.29 \pm 0.62$ & $3.60 \pm 0.32$ \\
\hline 2 & Oestrogen & 11 & $5.30 \pm 0.43$ & $0.79 \pm 0.13$ & $1.89 \pm 0.59$ \\
\hline 3 & Progesterone & 14 & $2.91 \pm 1.41$ & $2.33 \pm 0.80$ & $2.52 \pm 0.72$ \\
\hline 4 & Oestrogen + progesterone & 7 & $7.57 \pm 1.23$ & $2.05 \pm 1.28$ & $2.02 \pm 0.40$ \\
\hline
\end{tabular}

Values are mean \pm s.e.m. for 3 replicates.

$\uparrow$ Mean no. of embryos/replicate.

Summary of the analyses of variance:

\begin{tabular}{|c|c|c|c|c|}
\hline \multirow[b]{3}{*}{ Source of variation } & \multicolumn{4}{|c|}{ Variance ratios (logarithmic transformation) } \\
\hline & \multirow[b]{2}{*}{ d.f. } & \multicolumn{2}{|c|}{ Acid-soluble fraction } & \multirow{2}{*}{$\begin{array}{l}\text { Acid-insoluble } \\
\text { fraction }\end{array}$} \\
\hline & & Glycogen & Non-glycogen & \\
\hline Effect of hormones & (3) & & & \\
\hline Effect of oestrogen & 1 & $4 \cdot 74$ & 0.65 & $4 \cdot 44$ \\
\hline Effect of progesterone & 1 & $2 \cdot 48$ & $1 \cdot 68$ & $0 \cdot 35$ \\
\hline Interaction & 1 & $9 \cdot 59^{*}$ & 0.02 & 1.69 \\
\hline Between replicates & 2 & $2 \cdot 40$ & 0.61 & $2 \cdot 81$ \\
\hline $\begin{array}{l}\text { Replicate interactions } \\
\text { (error variance) }\end{array}$ & 6 & 0.0266 & $0 \cdot 1159$ & 0.0293 \\
\hline
\end{tabular}


transferred to untreated ovariectomized mice or those treated with oestrogen. Oestrogen antagonized the effect of progesterone and embryos transferred to mice simultaneously treated with oestrogen and progesterone had an accumulation of glucose carbon in this fraction similar to that in embryos transferred to untreated or oestrogen-treated animals. This effect showed as a significant interaction between the two hormones in the statistical analysis. Accumulation in the other fractions of these embryos varied considerably between replicates and none of the changes as a result of hormone treatments of the recipients tested was statistically significant.

\section{Experiment 2}

The label in the acid-soluble glycogen fraction decreased significantly during chase (Table 2). However, the degradation of this pool of glycogen was significantly higher $(P<0.01)$ after chase in vivo than after chase in vitro (means of 2.85 and $1.04 \mathrm{pg}$ atoms/embryo respectively). Furthermore, treatment with progesterone resulted in a significantly greater degradation of acid-soluble glycogen when compared to the ovariectomized control group $(P<0.05)$. Oestrogen priming of recipients

Table 2. Accumulation of glucose carbon in the biochemical fractions of pulse-labelled mouse morulaeearly blastocysts following chase in vitro or after transfer to oestrogen-primed or unprimed ovariectomized recipients treated with progesterone

\begin{tabular}{|c|c|c|c|c|c|}
\hline \multirow[b]{3}{*}{ Treatment } & \multirow[b]{3}{*}{$\mathrm{N} \dagger$} & \multicolumn{4}{|c|}{ Accumulation of glucose carbon ( $\mathrm{pg}$ atoms/embryo) in: } \\
\hline & & \multicolumn{2}{|c|}{ Acid-soluble fraction } & \multicolumn{2}{|c|}{ Acid-insoluble fraction } \\
\hline & & Glycogen & Non-glycogen & Glycogen & Non-glycogen \\
\hline $\begin{array}{l}\text { Pulse, } 2 \mathrm{~h} \\
\text { Chase, } 24 \mathrm{~h}\end{array}$ & 28 & $6.65 \pm 0.59$ & $4 \cdot 30 \pm 0.42$ & $1.99 \pm 0 \cdot 15$ & $3.57 \pm 0.75$ \\
\hline $\begin{array}{l}\text { In vitro } \\
\text { In vivo }\end{array}$ & 33 & $5.61 \pm 0.80$ & $0.67 \pm 0.09$ & $0.42 \pm 0.08$ & $1.70 \pm 0.08$ \\
\hline No hormone (Group A1) & 13 & $4.55 \pm 0.59$ & $0.60 \pm 0.05$ & $0.48 \pm 0.13$ & $1.87 \pm 0.38$ \\
\hline $\begin{array}{l}\text { Unprimed + progesterone } \\
\text { (Group A2) }\end{array}$ & 15 & $3.07 \pm 0.32$ & $1 \cdot 14 \pm 0 \cdot 14$ & $0.63 \pm 0.24$ & $3.10 \pm 0.53$ \\
\hline $\begin{array}{l}\text { Oestrogen primed + progesterone } \\
\text { (Group B) }\end{array}$ & 11 & $3.79 \pm 0.14$ & $1 \cdot 09 \pm 0.11$ & $0.60 \pm 0.20$ & $3 \cdot 25 \pm 1 \cdot 24$ \\
\hline
\end{tabular}

Values are mean \pm s.e.m. for 3 replicates.

$\dagger$ Mean no. of embryos/replicate.

Summary of the analyses of variance:

\begin{tabular}{|c|c|c|c|c|c|}
\hline \multirow[b]{3}{*}{ Source of Variation } & \multirow[b]{3}{*}{ d.f. } & \multicolumn{4}{|c|}{ Variance ratios (logarithmic transformation) } \\
\hline & & \multicolumn{2}{|c|}{ Acid-soluble fraction } & \multicolumn{2}{|c|}{ Acid-insoluble fraction } \\
\hline & & Glycogen & Non-glycogen & Glycogen & Non-glycogen \\
\hline Treatments & (4) & & & & \\
\hline Pulse versus chase & 1 & $30 \cdot 93^{* *}$ & $176 \cdot 49^{* *}$ & $47 \cdot 67^{* *}$ & $2 \cdot 62$ \\
\hline In-vitro versus in-vivo chase & 1 & $20 \cdot 29 * *$ & $6 \cdot 01^{*}$ & $1 \cdot 24$ & 1.87 \\
\hline Within in-vivo chase & & & & & \\
\hline Effect of progesterone & 1 & $9 \cdot 25^{*}$ & $20.99^{* *}$ & 0.84 & $2 \cdot 60$ \\
\hline Effect of priming & 1 & $4 \cdot 56$ & 0.09 & 0.00 & $0 \cdot 08$ \\
\hline Between replicates & 2 & $6.05^{*}$ & $0 \cdot 80$ & $7 \cdot 31^{*}$ & 3.44 \\
\hline $\begin{array}{l}\text { Replicate interactions } \\
\text { (error variance) }\end{array}$ & 8 & 0.0033 & 0.0068 & 0.0193 & 0.0308 \\
\hline
\end{tabular}

${ }^{*} P<0.05 ;{ }^{* *} P<0.01$ 
before the progesterone treatment had no significant effect on the accumulation of label in this fraction or on accumulation into any other biochemical fraction isolated.

A marked utilization of the glucose carbon accumulated in the non-glycogen acid-soluble component was observed during chase, both in vitro and in vivo (Table 2). Utilization of the label from this fraction was, overall, significantly higher after chase in vitro than in vivo because embryos transferred to ovariectomized mice treated with progesterone (Groups A2 and B) contained significantly more label in this component after chase than did embryos transferred to ovariectomized mice untreated with progesterone (Group A1).

The acid-insoluble glycogen fraction decreased significantly during chase both in vitro and in vivo (from $1.99 \mathrm{pg}$ atoms/embryo after pulse to a mean of $0.53 \mathrm{pg}$ atoms/embryo after chase, $P<$ 0.01 ). However, within in-vivo chase, treatment of recipients with hormones had no significant effect on accumulation into this fraction. Furthermore, incorporation into non-glycogen acidinsoluble compounds varied considerably. No significant change in the glucose carbon accumulated in this fraction was observed following chase in vitro or in vivo, even though the label remaining in this fraction after chase in progesterone-treated mice (Groups A2 and B) was almost double that in the other treatments.

\section{Discussion}

The present experiments clearly demonstrate that the progesterone-dominated uterine environment influences the turnover of glycogen in the developing embryo and that oestrogen administration at the time of transfer had no effect on glycogen metabolism. In fact, simultaneous administration of small amounts of oestrogen together with progesterone inhibited the effect of this second hormone on glycogen turnover.

Except for the effect of progesterone on glycogen metabolism, the administration of hormones to ovariectomized recipients had relatively little effect on the metabolism of the embryo. Oestrogen administration had no effect on any of the biochemical characteristics measured. On the other hand, progesterone did tend to maintain higher levels of label in the non-glycogen acid-soluble fraction during in-vivo chase. This effect could be a direct result of the stimulatinn to glycogen turnover in these circumstances leading to the accumulation of labelled metabolic intermediates in this pool. From inspection of the results of these experiments there was some indication that progesterone also increased the labelling of the non-glycogen acid-insoluble macromolecules. This effect was very variable and so did not appear as significant in the statistical analysis. However, stimulation of entry of isotope into this pool would not be unexpected given the evidence above that a stimulation of glycogen breakdown is associated with increased isotope levels in the pool of metabolic intermediates (non-glycogen acid-soluble pool) which could act as a source of labelled carbon for macromolecular synthesis. In other words, progesterone treatment of the recipient may have caused the channelling of substrate carbon from the storage compound, glycogen, through the metabolic intermediates in the acid-soluble fraction to the synthesis of macromolecules.

The label retained in the acid-soluble glycogen of morulae-early blastocysts after $24 \mathrm{~h}$ chase in ovariectomized mice treated with progesterone is similar to that observed when embryos at this stage were transferred to pseudopregnant mice for the same period of chase (Edirisinghe et al., 1984a). It would therefore appear that the high levels of progesterone in the mother before implantation cause increased degradation of glycogen in embryos and account for the low glycogen content of uterine embryos (Stern \& Biggers, 1968; Ozias \& Stern, 1973) in comparison to those cultured in vitro (Ozias \& Stern, 1973).

Most other evidence on the effects of hormones on the metabolism of uterine embryos has been obtained using embryos exhibiting implantational delay. Ozias \& Weitlauf (1971) found that treatment of mice with progesterone during implantational delay decreased the glycogen content of the embryos below that of controls. Considering the present findings that progesterone treatment 
increases glycogen turnover, the result reported for delayed embryos is not unexpected. The role of oestrogen is less clear. In embryos exhibiting delayed implantation, oestrogen has been shown to activate metabolism by increasing incorporation of precursors into RNA (Prasad, Dass \& Mohla, 1968; Dass, Mohla \& Prasad, 1969) and protein (Weitlauf \& Greenwald, 1968; Prasad et al., 1968; Dass et al., 1969) and by increasing the production of $\mathrm{CO}_{2}$ (Weitlauf, 1974; Torbit \& Weitlauf, 1974) and glycogen (Ozias \& Weitlauf, 1971). In the present experiment oestrogen caused no change in the metabolism of the preimplantation embryo in utero; its only effect was to reverse the effects of progesterone on embryonic metabolism.

The mechanism of action of progesterone on the metabolism of the developing embryo in vivo is not yet clearly understood. There are two possible ways that this hormone could influence the embryo: (1) it may have a direct effect on the embryo, or (2) it may act indirectly by changing the uterine milieu. The findings of Snyder, Weitlauf \& Nelson (1971) that the accumulation of glycogen in blastocysts retained in the oviducts of intact as well as hypophysectomized mice was greater than that in the uterus of intact animals indicate that a direct effect of progesterone on embryos in vivo is unlikely. These authors suggested that any systemic hormonal influences are mediated via the local environment. The results of the present Exp. 2 suggest that the unstimulated uterus accelerates glycogen breakdown above that occurring in vitro. The finding that this breakdown is further accelerated by the administration of progesterone suggests that progesterone may act indirectly by stimulating greater production of some, as yet unidentified, factor or factors responsible for the control of glycogen degradation.

The technical assistance of Rosalie Taylor is gratefully acknowledged. The work was aided by a grant from the Australian Research Grants Scheme. W.R.E. was supported by a Murdoch University Postgraduate Studentship.

\section{References}

Beier, H.M. (1974) Oviducal and uterine fluids. $J$. Reprod. Fert. 37, 221-237.

Dass, C.M.S., Mohla, S. \& Prasad, M.R.N. (1969) Time sequence of action of estrogen on nucleic acid and protein synthesis in the uterus and blastocyst during delayed implantation in the rat. Endocrinology 85, $528-536$.

Edirisinghe, W.R., Wales, R.G. \& Pike, I.L. (1984a) The degradation of biochemical pools in 8-cell and morula-early blastocyst stage embryos during culture in vitro and in vivo. J. Reprod. Fert. 72, 59-65.

Edirisinghe, W.R., Wales, R.G. \& Pike, I.L. (1984b) The synthesis and degradation of labelled glycogen pools in preimplantation mouse embryos during short periods of in vitro culture. Aust. J. biol. Sci. (in press).

Finn, C.A. (1977) The implantation reaction. In Biology of the Uterus, pp. 245-308. Ed. R. M. Wynn. Plenum Press, New York.

Finn, C.A. \& Martin, L. (1970) The role of the oestrogen secreted before oestrus in the preparation of the uterus for implantation in the mouse. J. Endocr. 47, $431-438$.

Finn, C.A. \& Martin, L. (1972) Endocrine control of the timing of endometrial sensitivity to a decidual stimulus. Biol. Reprod. 7, 82-86.

Fishel, S.B. (1979) Analysis of mouse uterine proteins at pro-oestrus, during early pregnancy and after administration of exogenous steroids. J. Reprod. Fert. 55, 91-100.
Iritani, A., Gomes, W.R. \& VanDemark, N.L. (1969) Secretion rates and chemical composition of oviduct and uterine fluids in ewes. Biol. Reprod. 1, 72-76.

Iritani, A., Nishikawa, Y., Gomes, W.R. \& VanDemark, N.L. (1971) Secretion rates and chemical compositions of oviduct and uterine fluids in rabbits. J. Anim. Sci. 33, 829-835.

McCormack, J.T. \& Greenwald, G.S. (1974) Evidence for a preimplantation rise in oestradiol-17 $\beta$ levels on Day 4 of pregnancy in the mouse. J. Reprod. Fert. 41, 297301.

Menke, T.M. \& McLaren, A. (1970) Carbon dioxide production by mouse blastocysts during lactational delay of implantation or after ovariectomy. J. Endocr. 47, 287-294.

Ozias, C.B. \& Stern, S. (1973) Glycogen levels of preimplantation mouse embryos developing in vitro. Biol. Reprod. 8, 467-472.

Oxias, C.B. \& Weitlauf, H.M. (1971) Hormonal influences on the glycogen content of normal and delayed implanting mouse blastocysts. J. exp. Zool. 177, 147152.

Pike, I.L. \& Wales, R.G. (1982) The uptake and incorporation of glucose especially into the glycogen pools of preimplantation mouse embryos during in vitro culture. Aust. J. biol. Sci. 35, 195-206.

Prasad, M.R.N., Dass, C.M.S. \& Mohla, S. (1968) Action of oestrogen on the blastocyst and uterus in delayed implantation-an auto-radiographic study. J. Reprod. Fert. 16, 97-103. 
Restall, B.J. (1966) The fallopian tube of the sheep. II. The influence of progesterone and oestrogen on the secretory activities of the fallopian tube. Aust. J. biol. Sci. 19, 187-197.

Restall, B.J. \& Wales, R.G. (1966) The fallopian tube of the sheep. III. The chemical composition of the fluid from the fallopian tube. Aust. J. biol. Sci. 19, 687-698.

Restall, B.J. \& Wales, R.G. (1968) The fallopian tube of the sheep. V. Secretion from the ampulla and isthmus. Aust. J. biol. Sci. 21, 491-498.

Shaikh, A.A. (1971) Estrone and estradiol levels in the ovarian venous blood from rats during the estrous cycle and pregnancy. Biol. Reprod. 5, 297-307.

Snyder, T.E., Weitlauf, H.M. \& Nelson, S.R. (1971) Comparison of the glycogen content of eggs in the uteri and oviducts of intact and hypophysectomized mice. Biol. Reprod. 5, 314-318.

Stern, S. \& Biggers, J.D. (1968) Enzymatic estimation of glycogen in the cleaving mouse embryo. J. exp. Zool. 168, 61-66.

Surani, M.A.H. (1975) Hormonal regulation of proteins in the uterine secretion of ovariectomized rats and the implications for implantation and embryonic diapause. J. Reprod. Fert. 43, 411-417.
Tantayaporn, P., Mallikarjuneswara, V.R., de Carlo, S.J. \& Clemetson, C.A.B. (1974) The effects of estrogen and progesterone on the volume and electrolyte content of of the uterine luminal fluid of the rat. Endocrinology 95, 1034-1045.

Torbit, C.A. \& Weitlauf, H.M. (1974) The effect of oestrogen and progesterone on $\mathrm{CO}_{2}$ production by delayed implanting mouse embryos. J. Reprod. Fert. 39, 379-382.

Wales, R.G. \& Restall, B.J. (1971) The uterus of the ewe. I. Secretion from the cannulated uterus. Aust. J. biol. Sci. 24, 1009-1021.

Weitlauf, H.M. (1974) Metabolic changes in the blastocysts of mice and rats during delayed implantation. $J$. Reprod. Fert. 39, 213-224.

Weitlauf, H.M. \& Greenwald, G.S. (1968) Influence of estrogen and progesterone on the incorporation of ${ }^{35} \mathrm{~S}$ methionine by blastocysts in ovariectomized mice. J. exp. Zool. 169, 463-470.

Yochim, J.M. (1975) Development of the progestational uterus: metabolic aspects. Biol. Reprod. 12, 106-133.

Received 29 December 1983 